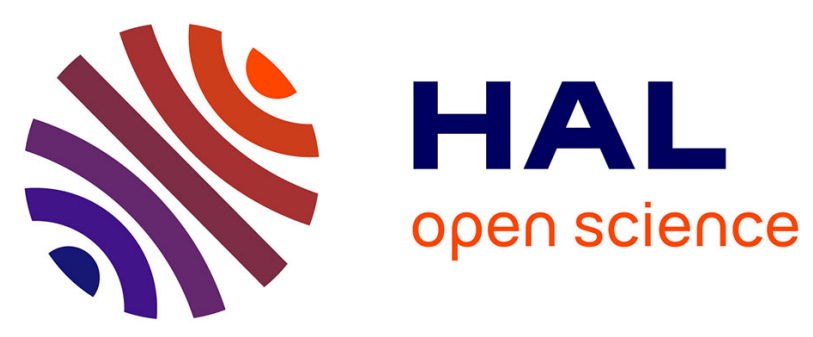

\title{
Rates of admission for ambulatory care sensitive conditions in France in 2009-2010: trends, geographic variation, costs, and an international comparison
}

William B. Weeks, Bruno Ventelou, Alain Paraponaris

\section{- To cite this version:}

William B. Weeks, Bruno Ventelou, Alain Paraponaris. Rates of admission for ambulatory care sensitive conditions in France in 2009-2010: trends, geographic variation, costs, and an international comparison. European Journal of Health Economics, 2016, 17 (4), pp.453-470. 10.1007/s10198-0150692-y . hal-01447863

\section{HAL Id: hal-01447863 \\ https://hal-amu.archives-ouvertes.fr/hal-01447863}

Submitted on 14 Mar 2019

HAL is a multi-disciplinary open access archive for the deposit and dissemination of scientific research documents, whether they are published or not. The documents may come from teaching and research institutions in France or abroad, or from public or private research centers.
L'archive ouverte pluridisciplinaire HAL, est destinée au dépôt et à la diffusion de documents scientifiques de niveau recherche, publiés ou non, émanant des établissements d'enseignement et de recherche français ou étrangers, des laboratoires publics ou privés. 


\title{
Rates of admission for ambulatory care sensitive conditions in France in 2009-2010: trends, geographic variation, costs, and an international comparison
}

\author{
William B. Weeks ${ }^{1,2,4}$ - Bruno Ventelou ${ }^{3,4}$ Alain Paraponaris ${ }^{3,4}$
}

Received: 22 July 2014/Accepted: 15 April 2015/Published online: 8 May 2015

(C) Springer-Verlag Berlin Heidelberg 2015

\begin{abstract}
Background Admissions for ambulatory care sensitive conditions (ACSCs) are considered preventable and indicators of poor access to primary care. We wondered whether per-capita rates of admission for ACSCs in France demonstrated geographic variation, were changing, were related to other independent variables, or were comparable to those in other countries; further, we wanted to quantify the resources such admissions consume.

Methods We calculated per-capita rates of admission for five categories (chronic, acute, vaccination preventable, alcohol-related, and other) of ACSCs in 94 departments in mainland France in 2009 and 2010, examined measures and causes of geographic variation in those rates, computed the costs of those admissions, and compared rates of admission for ACSCs in France to those in several other countries.

Results The highest ACSC admission rates generally occurred in the young and the old, but rates varied across French regions. Over the 2-year period, rates of most categories of ACSCs increased; higher ACSC admission rates were associated with lower incomes and a higher
\end{abstract}

William B. Weeks

wbw@dartmouth.edu

Bruno Ventelou

bruno.ventelou@inserm.fr

Alain Paraponaris

alain.paraponaris@inserm.fr

35 Centerra Parkway, Lebanon, NH 03766, USA

2 The Geisel School of Medicine at Dartmouth, Hanover, USA

3 SESSTIM, UMR 912, INSERM-IRD-Aix-Marseille Université, Marseille, France

4 The Aix-Marseille School of Economics, Marseille, France supply of hospital beds. We found that the local supply of general practitioners was inversely associated with rates of chronic and total ACSC admission rates, but that this relationship disappeared if we accounted for patients' use of general practitioners in neighboring departments. ACSC admissions cost 4.755 billion euros in 2009 and 5.066 billion euros in 2010; they consumed 7.86 and 8.74 million bed days of care, respectively. France had higher rates of ACSC admissions than most other countries examined. Conclusions Because admissions for ACSCs are generally considered a failure of outpatient care, cost French taxpayers substantial monetary and hospital resources, and appear to occur more frequently in France than in other countries, policymakers should prioritize targeted efforts to reduce them.

Keywords Ambulatory care sensitive conditions . Preventable admissions - Potential cost savings . International comparisons

JEL Classification I1 1 I18 $\cdot$ H51

\section{Introduction}

Geographic variation in use of healthcare resources has long been studied. In the US substantial geographic variation in utilization of services has been attributed to a feefor-service based reimbursement system that incentivizes over-utilization, lack of use of informed patient decisionmaking, and lack of consensus around acceptable practices [1-4]. Explanation of geographic variation in a variety of healthcare services in other OECD countries has been inconsistent [5]. However, France has been found to demonstrate less geographic variation than the US or UK in 
per-capita utilization rates of common elective surgical procedures [6]; the lower variation was attributed, in part, to greater centralized planning of hospital capacity in France.

Often referred to as preventable admissions or potentially avoidable hospitalizations, hospitalizations for ambulatory care sensitive conditions (ACSCs)—which refer to conditions for which hospitalization is often preventable, particularly when access to primary care is adequate [7, 8] - have been used as an indicator of access to and quality of primary care. In the US, factors associated with higher rates of ACSC hospitalization include a low primary care physician supply, high unemployment rates, and a higher proportion of the population who are uninsured $[9,10]$. In Canada, evaluation of a limited sample of ACSCs found that higher community affluence and not living in a rural setting were associated with lower rates of admission for ACSCs [11]. An Australian study found a 12-fold variation in admission rates for diabetes complications and similar variation in admission rates for asthma, influenza and pneumococcal pneumonia [12]; there, lower income, educational achievement, and self-rated health status were associated with higher rates of admission for ACSCs [13]. An evaluation of admission for several chronic ACSCs in four large Italian cities showed that poorer people, females, and older people in the sample were more likely to be admitted for ACSCs [14]. A largely observational study of patients aged 65 years old or older in 34 health districts in Madrid, Spain found that rates of preventable hospitalizations were higher for men, varied considerably, and were lower in central Madrid [15]. Wide variation in rates of admission for ACSCs was seen in Ireland, with lower rates being found in urban settings [16]. Gender and ethnicity have been associated with rates of admission for ACSCs in Singapore [17]. Overall rates of admission for ACSCs in Britain demonstrated substantial geographic variation, with lower income regions having higher rates; there, rates of admission for 'chronic' ACSCs have been stable over the last decade, but rates of admission for 'acute' and 'vaccination-preventable' ACSCs have increased [18, 19], causing management of ACSCs to become one of the top ten priorities for Britain's National Healthcare System [20]. Expansion of primary care access in Brazil reduced hospitalizations for ACSCs between 1999 and 2007 [21, 22]. When compared to unadjusted measures of rates of ACSCs in 26 cantons in Switzerland, researchers found that when they applied exclusion criteria or included information on comorbidities and health status, adjusted rates of ACSCs declined; however, they found no relationship between access to primary care physicians and rates of ACSCs [23]. Higher densities of specialists and generalists in Germany were associated with lower rates of hospitalization for a limited number of ACSCs, while unemployment, living in a rural setting, and the number of hospital beds per capita were associated with higher rates [24]. A study of three metropolitan regions in France found an association between lower supply of primary care physicians and higher rates of admission for a limited number of ACSCs [25]. Finally, a study that examined potentially avoidable hospitalization rates for six reasons in Denmark, England, Portugal, Slovenia, and Spain in 2009 found substantial variation across and within countries: within countries, educational level and income and overall use of hospitals for care were associated with potentially avoidable hospitalization rates [26]. An examination of geographic variation in rates of hospitalization for ACSCs across all of France, the costs of those hospitalizations, and a comparison of rates in France to those in other countries has not been conducted.

To address this knowledge gap, we used data on admissions to French hospitals to identify admissions for ACSCs, determine the costs of those admissions, calculate measures of geographic variation in those admissions, and discern whether a number of independent variables (including measures of local income, hospital bed capacity, and primary care physician supply) were associated with that variation.

\section{Materials and methods}

\section{Data sources, sample definition, and variables}

Using a dataset of all discharges from public and private sector French hospitals in 2009 and 2010 obtained from the Agence Technique de l'Information sur l'Hospitalisation [27], we used the primary ICD-10 coded diagnosis and a published ICD-10 code to ACSC crosswalk [7] to identify admissions for a variety ACSCs. We followed the British system of aggregating admissions for ACSCs to acute, chronic, and vaccination-preventable categories [18]. We also examined admissions for alcohol-related ACSCs, for two reasons. First, alcohol and mental health disorders are common [28], are projected to account for substantial disability across all World Bank Income level countries through 2030 [29], and are increasingly prevalent and costly within the European Union. Second, France experiences the third highest total costs (including direct medical, direct nonmedical, and indirect costs), associated with these disorders in the European Union, behind Germany and the UK [30]. We therefore thought that understanding geographic variation in alcohol-related ACSCs would be particularly relevant in France. Therefore, to be as comprehensive as possible, we included both alcohol-related ACSCs and 'other' ACSCs (those defined elsewhere [7], but not falling into any of the other categories) in our analysis. 
Table 1 shows the ICD-10 definitions of categories of ACSCs that we studied.

\section{Analytic methods}

\section{Calculation of utilization rates}

We used an indirect method [31] to retrospectively calculate age- and sex-adjusted department-level rates of admission for ACSCs, using age- and sex-specific French national rates as standard rates. For 94 "departments" in mainland France, we calculated ACSC admission rates using this age- and sex-adjusted number of admissions as the numerator and the age- and sex-specific departmentlevel population estimates from the French census [32] as the denominator. As France does not collect information on race, we could not adjust for geographic differences in race prevalence. Following Dartmouth Atlas methods [33] percapita rates were calculated based on where people lived, as opposed to where they might have sought care. We calculated the annual number of admissions for ACSCs and the annual department-level rate of admission for ACSCs per 1000 people for 2009 and 2010.

\section{Calculation of supply variables}

We used two methods to calculate department-specific percapita supply of medical beds and general practitioners. First, following Dartmouth Atlas methods that address the possibility that patients living in one region might seek care in another because of limited resources in their own region [33], from the 2010 annual survey of French hospitals [34],

Table 1 Categorization of admissions for ACSCs and ICD-10 codes used to identify them

\begin{tabular}{|c|c|c|}
\hline Admission for & $\begin{array}{l}\text { Category of } \\
\text { ACSC }\end{array}$ & ICD-10 codes used to identify ACSCs [7] \\
\hline Angina & Chronic & $\mathrm{I} 20, \mathrm{I} 24.0, \mathrm{I} 24.8, \mathrm{I} 24.9$ \\
\hline Asthma & Chronic & $\mathrm{J} 45, \mathrm{~J} 46$ \\
\hline Congestive heart failure & Chronic & I11.0, I50, J81 \\
\hline Convulsion and epilepsy & Chronic & G40, G41, R56, O15 \\
\hline $\begin{array}{l}\text { Chronic obstructive pulmonary } \\
\text { disease }\end{array}$ & Chronic & $\mathrm{J} 20, \mathrm{~J} 41, \mathrm{~J} 42, \mathrm{~J} 43, \mathrm{~J} 47$ \\
\hline Diabetes complications & Chronic & E10.0-E10.8, E11.0-E11.8, E12.0-E12.8, E13.0-E13.8, E14.0-E14.8 \\
\hline Hypertension & Chronic & I10, I11.9 \\
\hline Iron-deficiency anemia & Chronic & D50.1, D50.8, D50.9 \\
\hline Cellulitis & Acute & L03, L04, L08.0, L08.8, L08.9, L88, L98.0 \\
\hline Dehydration & Acute & E86 \\
\hline Nonspecific gastroenteritis & Acute & K52.2, K52.8, K52.9 \\
\hline Kidney/urinary infection & Acute & N10, N11, N12, N13.6 \\
\hline Dental conditions & Acute & A69.0, K02, K03, K04, K05, K06, K08, K09.8, K09.9, K12, K13 \\
\hline Ear, nose and throat infections & Acute & H66, H67, J02, J03, J06, J31.2 \\
\hline Gangrene & Acute & R02 \\
\hline Nutritional deficiency & Acute & $\mathrm{E} 40, \mathrm{E} 41, \mathrm{E} 42, \mathrm{E} 43, \mathrm{E} 55.0, \mathrm{E} 64.3$ \\
\hline Pelvic inflammatory disease & Acute & N70, N73, N74 \\
\hline Perforated/bleeding ulcer & Acute & $\begin{array}{l}\text { K25.0-K25.2, K25.4-K25.6, K26.0-K26.2, K26.4-K26.6, K27.0-K27.2, K27.4- } \\
\text { K27.6, K280-282, K284-K286 }\end{array}$ \\
\hline Influenza and pneumonia & Vaccine & J10, J11, J13, J14, J15.3, J15.4, J15.7, J15.9, J16.8, J18.1, J18 \\
\hline Other vaccine-preventable diseases & Vaccine & A35, A36, A37, A80, B05, B06, B16.1, B16.9, B18.0, B18.1, B26, G00.0, M01.4 \\
\hline Alcohol-related diseases & Alcohol & F10 \\
\hline Atrial fibrillation and flutter & Other & I47.1, I47.9, I49.5, I49.8, I49.9, R00.0, R002, R00.8 \\
\hline Constipation & Other & K59.0 \\
\hline Fractured proximal femur & Other & $\mathrm{S} 72.0, \mathrm{~S} 72.1, \mathrm{~S} 72.2$ \\
\hline $\begin{array}{l}\text { Dyspepsia and other stomach } \\
\text { function disorders }\end{array}$ & Other & $\mathrm{K} 30, \mathrm{~K} 21$ \\
\hline Hypokalemia & Other & E87.6 \\
\hline Migraine/acute headache & Other & G43, G44.0, G44.1, G44.3, G44.4, G44.8, R51x \\
\hline
\end{tabular}


we determined whether patients who were admitted for an ACSC lived in the same department as their admission. We then used this information to reallocate beds to the region or department where the patient lived (for an example, see "Appendix"). Similarly, we obtained information on the department-specific supply of general practitioners in 2010 from "Eco-Santé" [35] and used the same methods that we used to reassign beds to reallocate general practitioners. Then, using reallocated medical hospital beds and general practitioners in the numerator and department-specific populations in the denominator, we calculated the percapita supply of these reallocated healthcare resources at the department level. For each of these supply variables, we also calculated the non-reallocated per-capita supply of these healthcare resources by dividing the number of beds or general practitioners in the department by the department-specific population. All per-capita supply measures were converted into the supply per 1000 population by multiplying the per-capita supply by 1000 .

\section{Measures of geographic variation}

For individual categories of ACSCs and all of them together, we report age-sex adjusted national per-capita rates and four established measures of geographic variation that allow for comparison across geographic settings and countries [36-38]:

1. The extreme ratio, which is calculated by dividing the highest geographic rate by the lowest and represents the range of absolute service utilization levels.

2. The interquartile ratio, which is calculated by dividing the rate at the 75 th percentile by that at the 25 th percentile and shows the relative variation in service utilization after removing the most extreme values.

3. The coefficient of variation, which is the ratio of the standard deviation to the mean and represents a normalized version of dispersion.

4. The systematic component of variation (SCV), which shows the non-random part of variation in rates by distinguishing the systematic variation between areas from the random variation within areas [38]. As is common practice, we multiplied SCV by 10 .

For the first three measures examined, higher numbers all indicate greater levels of geographic variation; however, these measures do not specifically address the nonrandom aspects of geographic variation and they may be influenced by extreme values. The SCV measure addresses both of these issues: an $\mathrm{SCV} \times 10$ greater than 5 indicates high variation; that greater than 10 , very high variation.

\section{Comparison of rates across independent variables and regression analyses}

We explored the relationship between admission rates for different categories of ACSCs, healthcare resources, and several departmental level independent variables that we obtained from the Association Nationale des Directeurs d'Action Sociale et de Santé des Conseils généraux [39], including: population density, department-level median income, inter-decile income ratio (the ratio of the mean highest decile income to the mean lowest decile income), and the proportion of older citizens who are enrolled in the ASPA subsidy program (a social program for aged people whose income is below a minimum level). We used spatial regression analytic techniques $[40,41]$ to determine whether the likelihood ratio test for spatial lag dependence (which indicates that proximal departments influence the results of one another) was statistically significant at $p<0.05$. If it was, we used a first-order 'queen-based contiguity matrix', wherein immediately adjacent departments are the basis for the spatial matrix when conducting spatial regression analyses; if it was not, we performed ordinary least squared regression analysis. Using the appropriate regression techniques, we then examined relationships between the five categories of ACSC admission rates (and the total of these) as the dependent variable. We ran two regression models, one that used reallocated supply measures and one that used non-reallocated supply measures. We used SPSS v21 (released 2012, Armonk, NY: IBM Corporation) for all comparisons save the spatial regression analyses, which used GeoDa v1.4.6 (released 2013, Tempe, AZ: Arizona State University) [42].

\section{Calculation of costs of these admissions}

France has for-profit and not-for-profit hospitals that are reimbursed differently based on a DRG-like Groupe Homogène des Malades (GHM) that is captured in the dataset that we used; the GHM reimbursement rates change yearly. As our dataset included the hospital identifier for each admission, we were able to determine which hospitals were for-profit and which were not-for-profit. We then applied the year-specific for-profit or not-for-profit (depending on in which type of hospital the admission occurred) GHMspecific mean total (including physician services) reimbursement rate that we obtained from the Agence Technique de l'Information sur l'Hospitalisation [27]. Then, we summed the overall national costs for admissions to forprofit and not-for-profit hospitals for different categories of ACSCs that occurred in mainland France in 2009 and 2010. Our dataset also included the length of stay for each admission, so we used length of stay data to determine the total number of bed days of care consumed by each 
category of ACSC in for-profit and not-for-profit hospitals for 2009 and 2010.

\section{International comparisons}

Prior studies of rates of admission for ACSCs have examined different age groups to calculate denominators and have used various definitions of what constitutes an ACSC to calculate numerators (Table 2). To make international comparisons, we mimicked the definitions of ACSCs that were described in those studies and used the age groupings that they had used to calculate rates of externally defined ACSCs in France for 2009 and 2010 that were specific to the comparator.

\section{Human subjects approval}

In the United States, the Institutional Review Board (IRB) at Dartmouth College approved this study, determining that, because of the anonymized nature of the dataset, it was not human subjects research (CPHS approval number 24085). In France, the study and its use of anonymized data was approved by the French National Union of Regional Health Observatories (Fédération Nationale des Observatoires Régionaux de la Santé) and the French IRB (Commission Nationale Informatique et Libertés, National Committee for Data Files and Individual Liberties) (CNIL authorization number 1180745).

\section{Results}

\section{Counts, rates, and measures of geographic variation}

In 2009, hospitals in mainland France had 1,585,413 admissions for the ACSCs that we examined; in 2010, there were 1,635,047 such admissions, a $3.13 \%$ increase. Age group- and gender-specific counts of admissions for ACSCs in 2009 and 2010 are shown in Fig. 1a. A U-shaped distribution across the lifespan, with higher numbers of admissions occurring in the very young and very old, is evident; further, with the exception of the 12-29 and the 80-99 age groups, counts for males were higher than those for females. Categories of ACSCs had their own patterns: for instance numbers of admissions for chronic ACSCs tended to increase with age while those for acute tended to decrease; admissions for vaccine-preventable ACSCs peaked at the extremes of life, while those for alcoholrelated ACSCs peaked in midlife and were more common among men. Per-capita rates of admission for ACSCs generally increased with increasing age (after the age 0-5 category); males had higher rates of admission for ACSCs except in the 6- to 29-year-old age groups (Fig. 1b).
Admission rates for chronic and vaccine-preventable ACSCs accounted for the large majority of all admissions for ACSCs beginning at about age 50. Across years, counts and rates of admissions for ACSCs were fairly stable in the younger age groups, but increased in the older age groups.

Figure 2 shows geographic variation in age- and sexadjusted rates of admission for the five categories of ACSCs that we examined. With the exception of vaccinepreventable ACSCs, age- and sex-adjusted per-capita rates of all categories of ACSCs increased from 2009 to 2010. Over the 2-year period, rates of admission for alcohol-related ACSCs increased by $8.9 \%$; other, by $3.1 \%$; acute, by $3.7 \%$, and chronic, by $3.1 \%$. Interquartile ratios and coefficients of variation remained stable across years. Except for alcohol-related ACSC admissions, the systematic component of variation was considered low $(<5.0)$; it decreased for all types of ACSCs between 2009 and 2010. Figure 3 shows maps that indicate higher rates of total ACSCs in the north of France. However, each ACSC category has a unique geographic pattern: for instance, northeast France had relatively higher rates of admission for chronic ACSCs, southeast France had relatively higher rates of admission for acute and other ACSCs, and northwest France had relatively higher rates of admission for alcohol-related ACSCs.

\section{Costs and resource consumption}

Admissions for the ACSCs that we examined cost 4.755 billion euros in 2009 and 5.066 billion euros in 2010 (Fig. 4). The vast majority of those costs were due to admissions that occurred in not-for-profit hospitals; admissions to for-profit hospitals accounted for less than $15 \%$ of total costs each year. Regardless of the type of hospital examined, admissions for chronic ACSCs accounted for about $50 \%$ of total costs of all ACSC admissions; those for acute ACSCs accounted for about $14 \%$ of total costs of all ACSC admissions. When compared to for-profit hospitals' total costs, a higher proportion of not-for-profit hospitals' total costs for ACSCs were spent on alcohol-related ACSCs (about $5 \%$ each year vs $0.3 \%$ in 2009 and $1.4 \%$ in 2010), but a lower proportion was expended on admissions for the 'other' ACSCs that we examined (less than $20 \%$ vs about $33 \%$ of total costs in both years). ACSC admissions consumed 7.86 million bed days of care in 2009 and 8.74 million bed days of care in 2010. Admissions for chronic ACSCs consumed about $50 \%$ of the total bed days of care consumed for all ACSCs admissions that we examined, regardless of the type of hospital examined. Patterns of consumption of bed days of care tracked those of costs, with the exception that admissions for alcohol-related ACSCs consumed relatively more bed days of care (6.4 and $6.3 \%$ of not-for-profit hospitals' total bed days of 


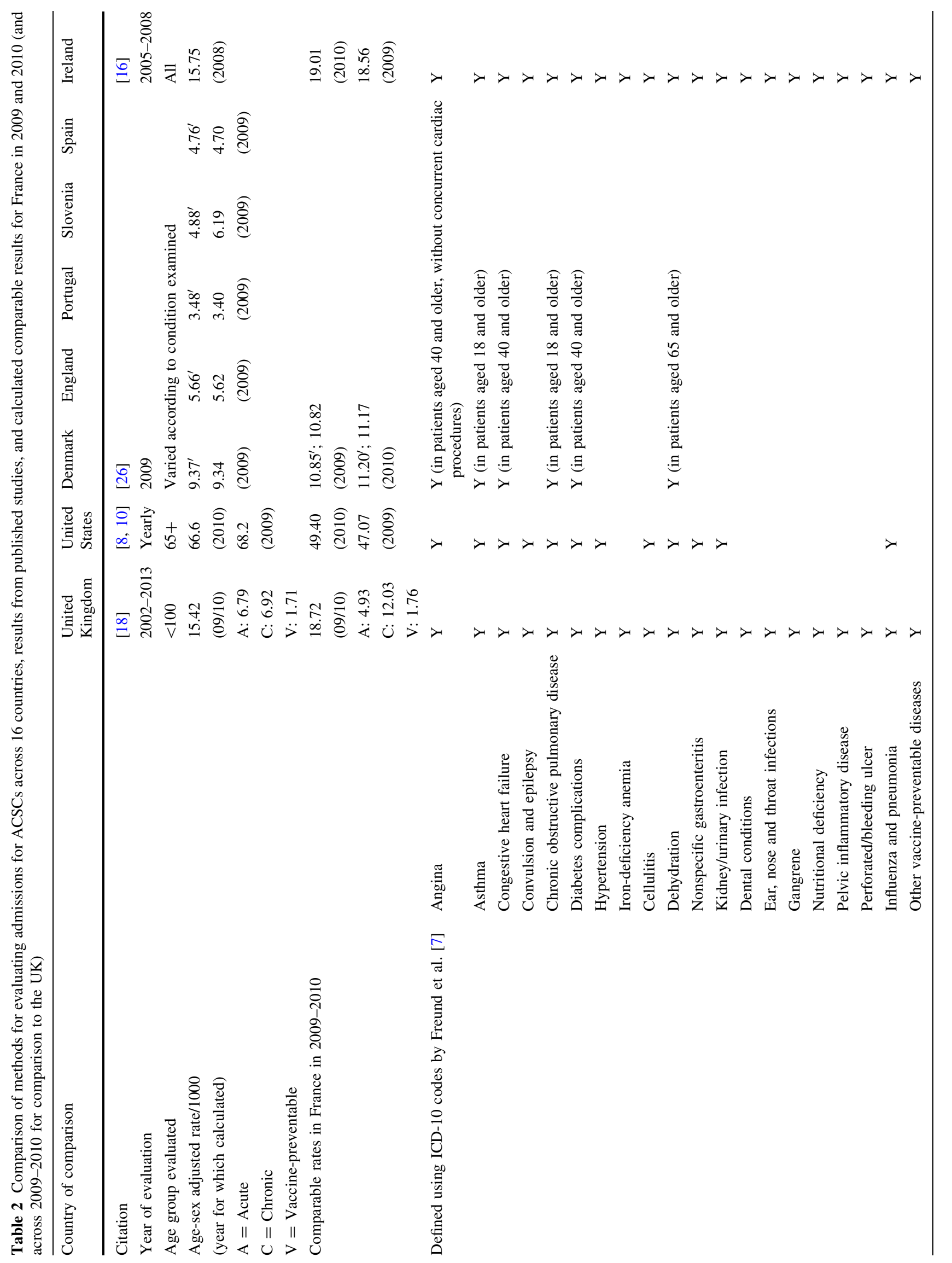


Rates of admission for ambulatory care sensitive conditions in France in 2009-2010: trends...

459

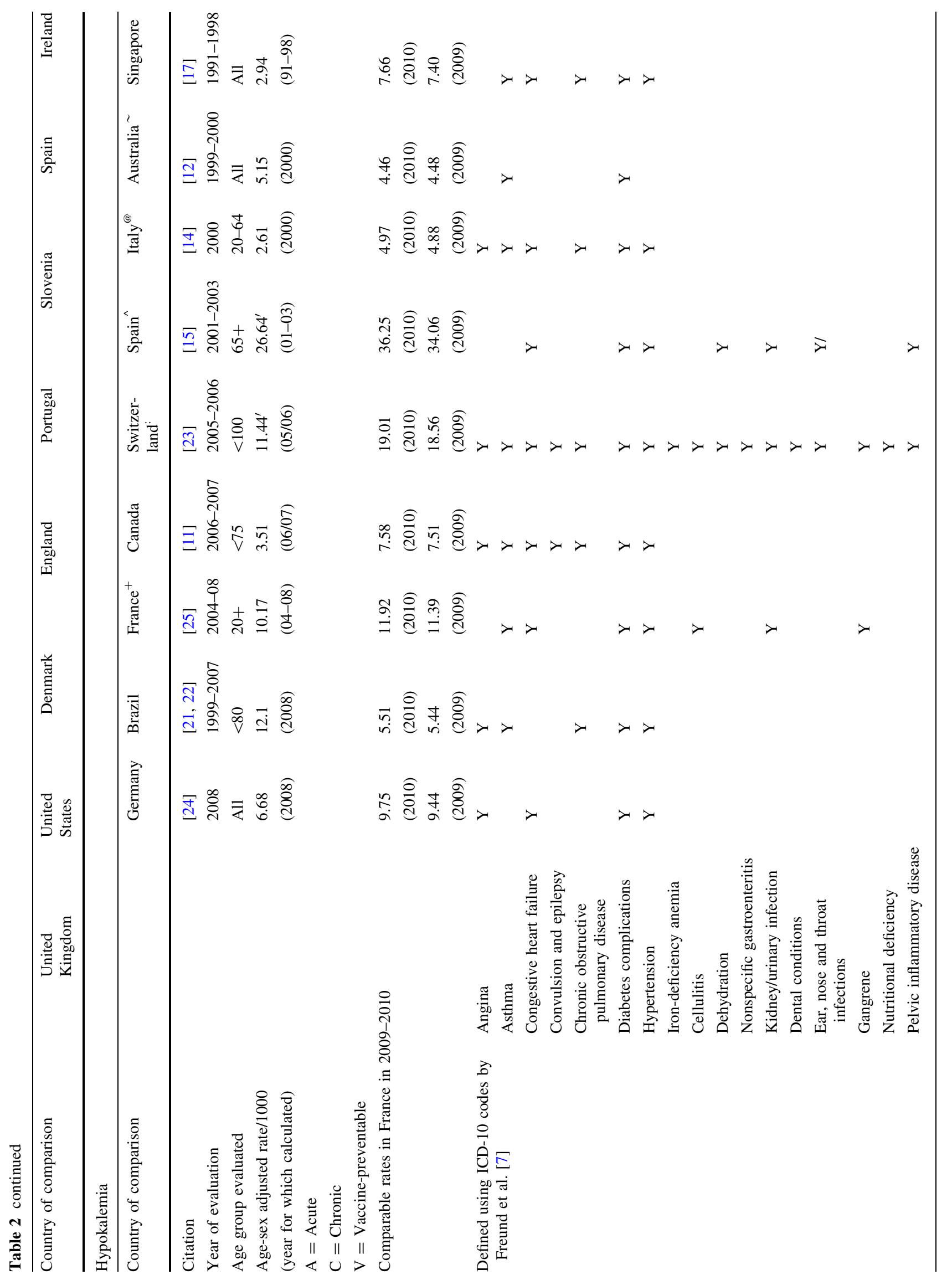

Springer 


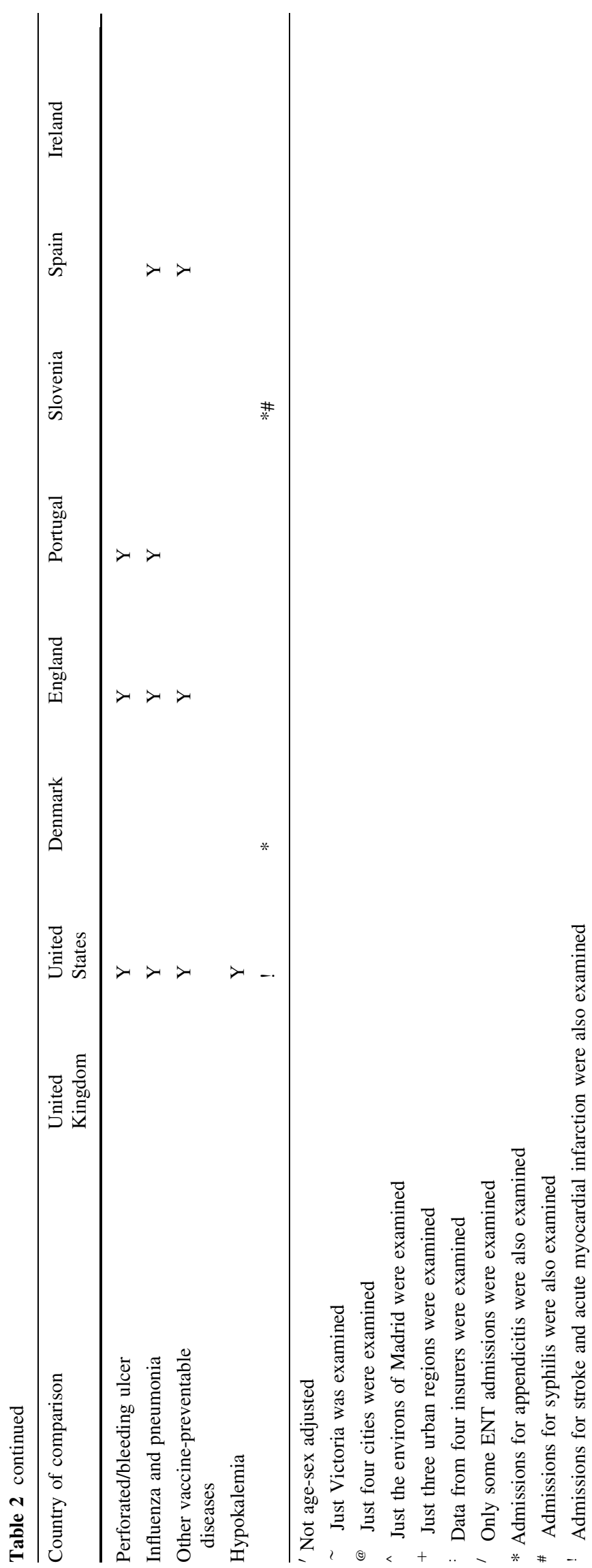


care and 1.7 and $2.0 \%$ of for-profit hospitals' bed days of care in 2009 and 2010, respectively) than they did costs.

From year to year, costs for all examined ACSCs increased by $6.5 \%$ and overall bed days of care increased by $11.1 \%$. Annual increases were highest for acute and alcohol-related ACSCs where costs increased by 14.3 and $14.0 \%$ and bed days of care increased by 18.0 and $11.3 \%$, respectively.

\section{Comparison of rates across independent variables and regression analyses}

Regardless of whether our regression models use reallocated or non-reallocated supply variables, the likelihood ratio test indicated that spatial regression techniques should be used for analysis of chronic, alcohol-related, other, and total ACSCs in 2009 and 2010 and for analysis of acute ACSCs in
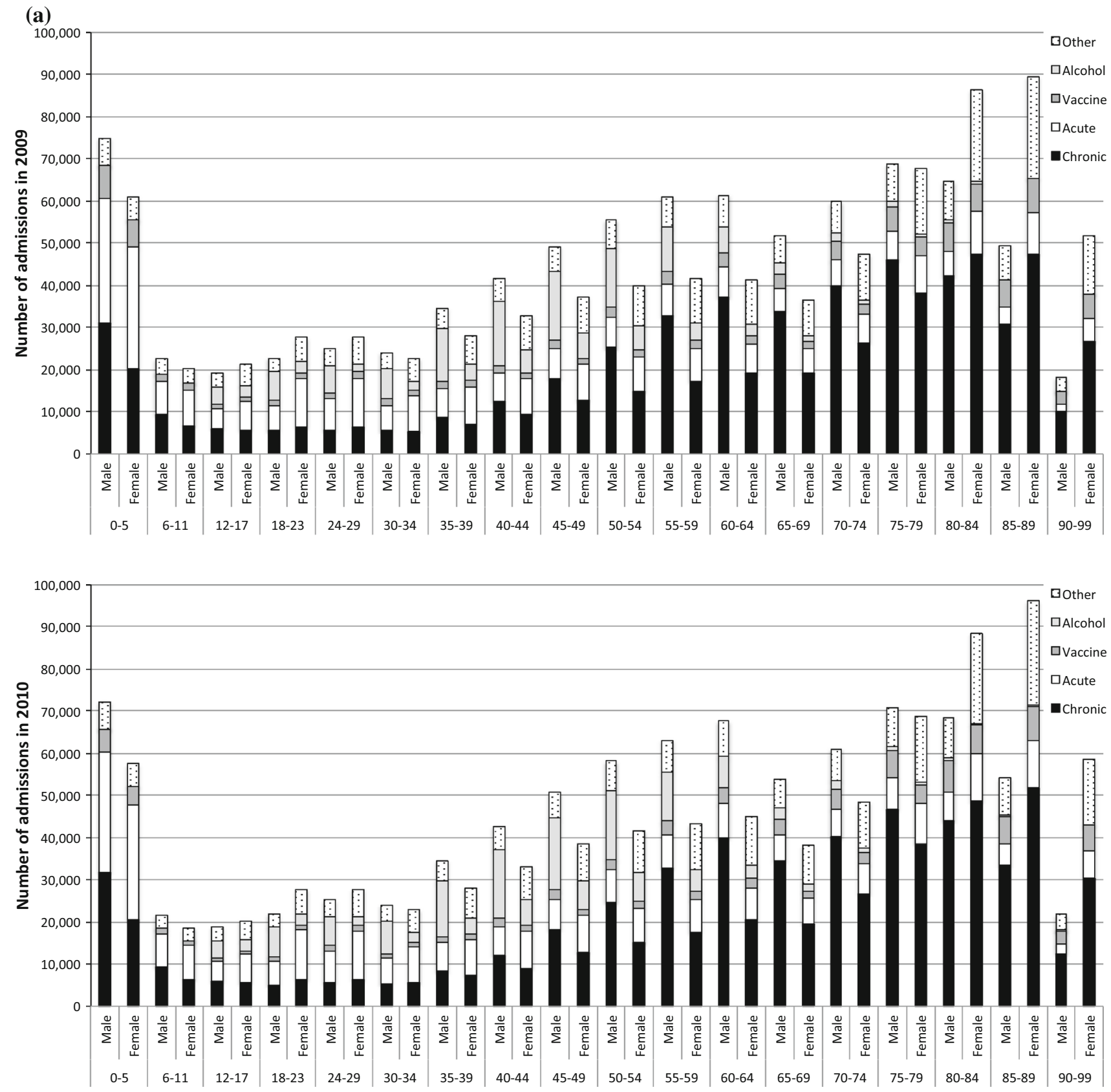

Fig. 1 a For 2009 and 2010, by age category examined, number of admissions for chronic, acute, vaccine-preventable, alcohol-related, and other ACSCs in mainland France. b For 2009 and 2010, by age category examined, rate of admissions per 1000 for chronic, acute, vaccine-preventable, alcohol-related, and other ACSCs in mainland France 



Fig. 1 continued

2009; ordinary least squared regression techniques were used to analyze vaccine-preventable ACSCs in 2009 and 2010 and acute ACSCs in 2010 (Table 3). Higher total percapita rates of admissions for the ACSCs we examined were associated with lower population density, lower departmentlevel median incomes, higher inter-decile income ratios, lower proportions of older residents enrolled in ASPA, and higher numbers of medical beds per capita. For individual ACSC categories, lower incomes were associated with higher rates of chronic, acute, and 'other' ACSCs in both years, as well as with rates of alcohol-related ACSC in 2010. Higher measures of income disparities were most strongly related to higher rates of chronic, acute, and 'other' ACSCs. A greater degree of enrollment of older citizens in ASPA was associated with lower rates of chronic and acute ACSCs. These relationships prevailed regardless of whether we used reallocated or non-reallocated resource supply measures. When examining the medical bed supply, we found that higher numbers of medical beds per capita were associated with higher rates of chronic, alcohol-related, and total 
Fig. 2 Geographic variation in age-sex adjusted rates per 1000 population of different categories of ACSCs for 94 departments in mainland France in 2009 and 2010. Above, the open circles show the rates of highest and lowest departments, the whiskers show plus and minus one standard deviation, and the horizontal lines in the boxplot show 75th, 50th, and 25th percentiles. Below, for each category and year, the national age-sex adjusted average rate per 1000 population, the standard deviation, the coefficient of variation, the rates for the departments with the lowest and highest rates, and systematic component of variation $\times 10$ are provided

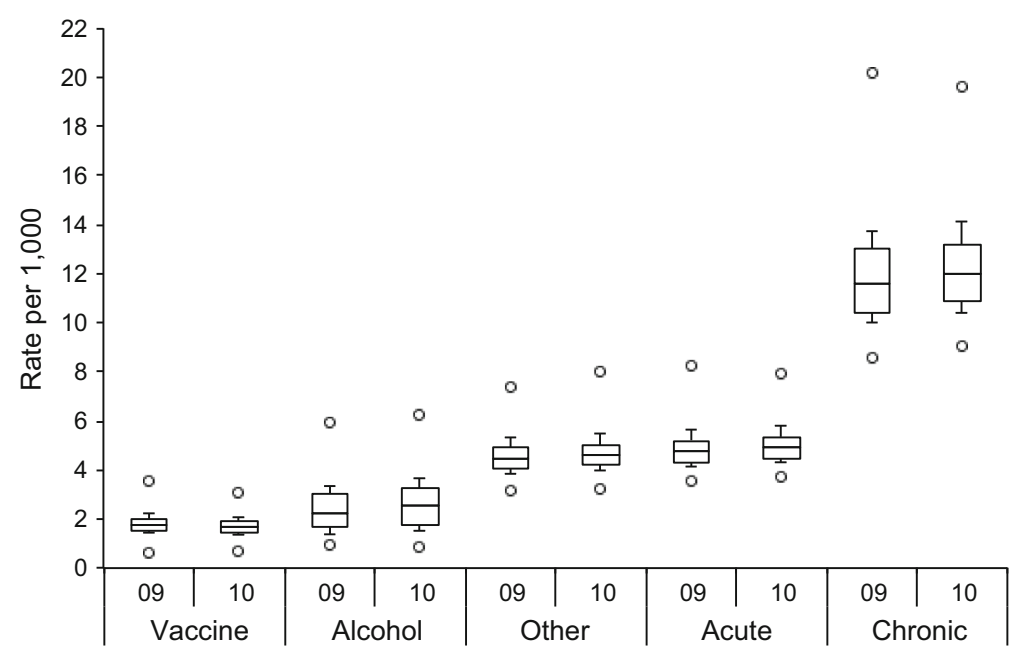

\begin{tabular}{|l|c|c|c|c|c|c|c|c|c|c|}
\hline $\begin{array}{l}\text { National age-sex } \\
\text { adjusted mean rate } \\
\text { per 1,000 }\end{array}$ & 1.80 & 1.71 & 2.36 & 2.57 & 4.59 & 4.73 & 4.88 & 5.06 & 11.87 & 12.24 \\
\hline $\begin{array}{l}\text { Lowest department } \\
\text { rate per 1,000 }\end{array}$ & 0.61 & 0.74 & 0.99 & 0.92 & 3.17 & 3.29 & 3.59 & 3.71 & 8.60 & 9.04 \\
\hline $\begin{array}{l}\text { Highest department } \\
\text { rate per 1,000 }\end{array}$ & 3.56 & 3.11 & 5.99 & 6.28 & 7.41 & 8.00 & 8.22 & 7.93 & 20.18 & 19.57 \\
\hline Extreme ratio & 5.82 & 4.20 & 6.07 & 6.81 & 2.34 & 2.43 & 2.29 & 2.14 & 2.35 & 2.16 \\
\hline Interquartile ratio & 1.29 & 1.29 & 1.80 & 1.82 & 1.21 & 1.20 & 1.21 & 1.20 & 1.25 & 1.21 \\
\hline $\begin{array}{l}\text { Coefficient of } \\
\text { variation }\end{array}$ & 0.22 & 0.21 & 0.40 & 0.41 & 0.16 & 0.16 & 0.16 & 0.15 & 0.16 & 0.15 \\
\hline $\begin{array}{l}\text { Systematic } \\
\text { component of } \\
\text { variation (x10) }\end{array}$ & 4.88 & 4.55 & 16.26 & 16.68 & 2.35 & 2.31 & 2.24 & 1.99 & 2.28 & 2.15 \\
\hline
\end{tabular}

ACSCs in both years regardless of whether we used reallocated or non-reallocated measures of bed supply; vaccinerelated ACSC rates were statistically significantly related to the reallocated bed supply but not to non-reallocated bed supply in both years. We found that higher numbers of reallocated general practitioners per capita were statistically associated only with lower rates of alcohol-related ACSCs; however, the non-reallocated per-capita supply of general practitioners was also inversely statistically significantly associated with chronic ACSCs, and rates in both years and total rates in 2009. Results that used non-reallocated supply measures generally accounted for less of the variance in the models than did those that used reallocated supply measures.

\section{International comparisons}

While exact comparisons of rates were impossible in some cases (when, for instance, age- or sex-adjustment was not used or additional ACSCs beyond those that we examined were also included), France demonstrated higher rates of admission for ACSCs than all countries save the United States, Brazil, and Australia (but, in the case of Brazil, a number of relatively common admission types, including stroke and acute myocardial infarction, were included in the Brazilian definition of ACSCs; with Australia, comparisons were made to results from a decade previous)
(Table 2). However, as can be seen when comparing French to UK rates for 2009-2010, the composition of the ACSCs might differ across countries: when compared to the UK, France had lower rates of admission for acute ACSCs, but substantially higher rates of admission for chronic ACSCs and similar rates of admission for vaccinepreventable ACSCs. Depending on the year and the country, France's rates of admission for comparably defined ACSCs in 2009 ranged from $12 \%$ (when compared to Ireland in 2005-2008) to $221 \%$ (when compared to Portugal in 2009) higher than that seen in other countries. The table also demonstrates the effect of using different inclusion criteria and age groups for determination of percapita rates of admission for ACSCs: in France, in 2010, rates calculated using different definitions and age groups varied from 4.46 per 1000 when using the Australian definition of ACSCs across the entire age spectrum to 49.40 per 1000 when using the US definition of ACSC in the 65-year-old and older age group.

\section{Discussion}

We examined five categories of admissions for ACSCs in mainland France in 2009 and 2010 and found that numbers of such admissions tend to peak at the extremes of life and 
Fig. 3 Geographic variation in rates of ACSCs in France in 2010. Lightest indicates lowest quintile of per-capita rates; darkest indicates highest quintile of per-capita rates

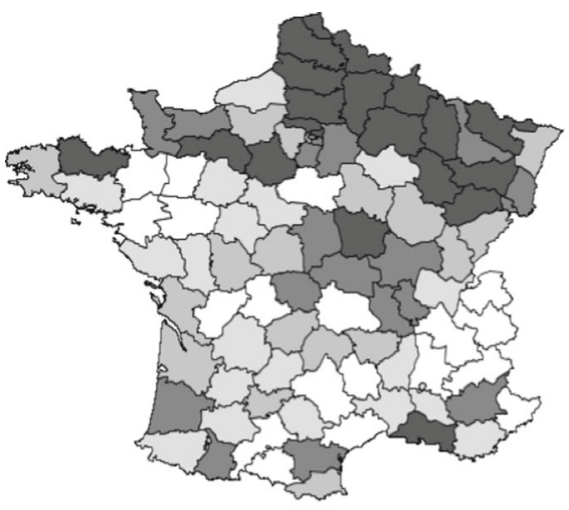

Chronic ACSCs

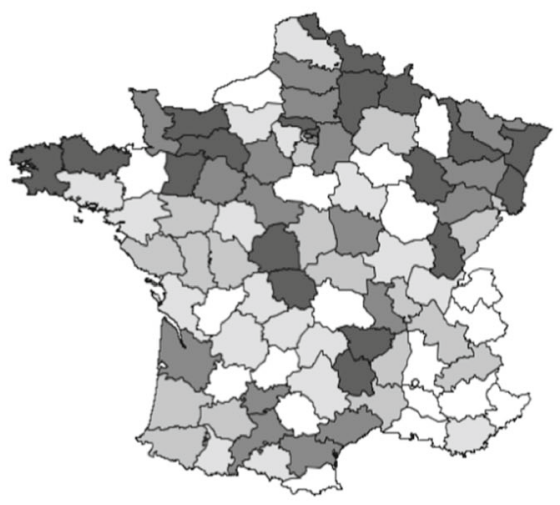

Vaccine preventable ACSCs

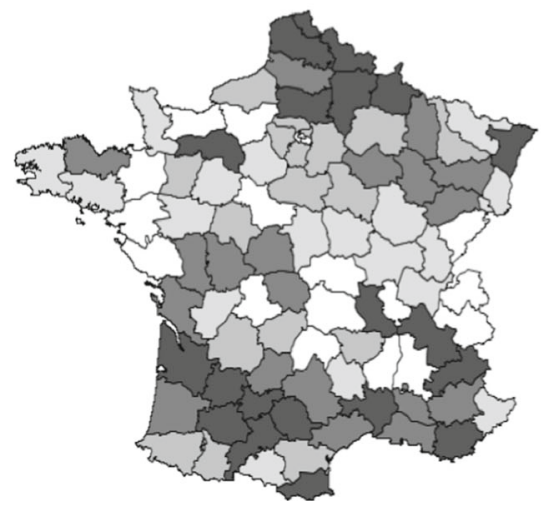

Other ACSCs

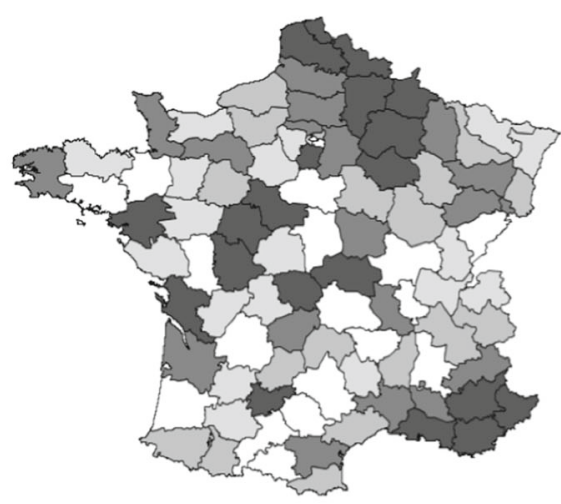

Acute ACSCs

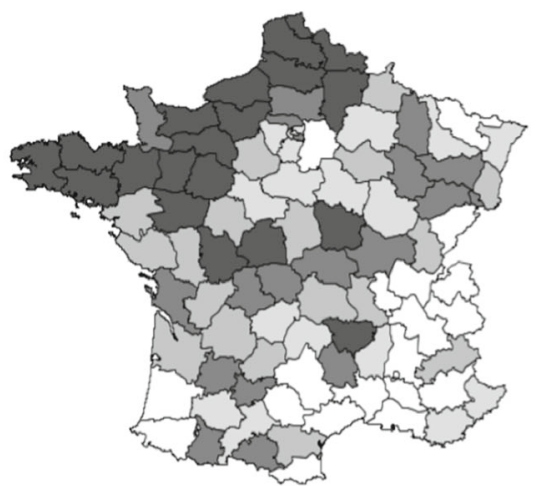

Alcohol related ACSCs

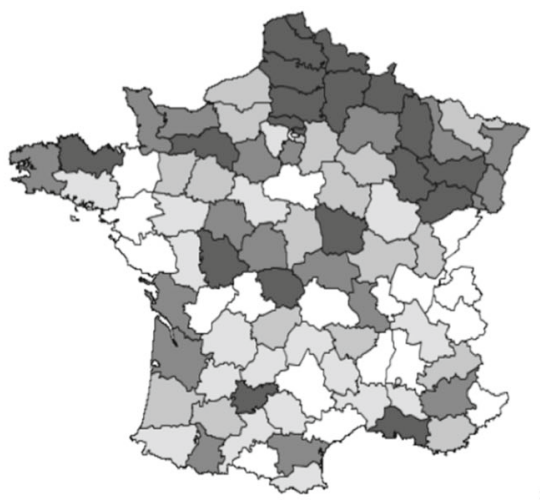

Total ACSCs per-capita rates of such admissions peak near the end of life. We found relatively low levels of systematic geographic variation (as measured by the SCV) at the departmental level in rates of admission overall and for all categories of admission for ACSCs except for those for alcohol-related ACSCs; nonetheless, we did find that numbers and rates of specific categories of ACSCs are age, gender-, and region-specific. For instance, admissions for alcohol-related ACSCs peaked in midlife, were primarily seen in males, and were most prevalent in the northwest region of France; admissions for chronic ACSCs peaked at the end of life and were more prevalent in the northeast region of France.

The larger regional patterns that we saw in per-capita admissions for chronic, acute, and alcohol-related ACSCs warrants some comment. While our regression models suggest that some of the explanation of the regional variation we saw in admission for chronic and acute ACSCs might be explained by low population density or higher per-capita bed supply, it is possible that regional cultural 
Fig. 4 In 2009 and 2010, total cost of admissions for (top) and total bed days of care consumed by (bottom) admissions to notfor-profit and for-profit hospitals in mainland France for chronic, acute, vaccine-preventable, alcohol-related, and other ACSCs
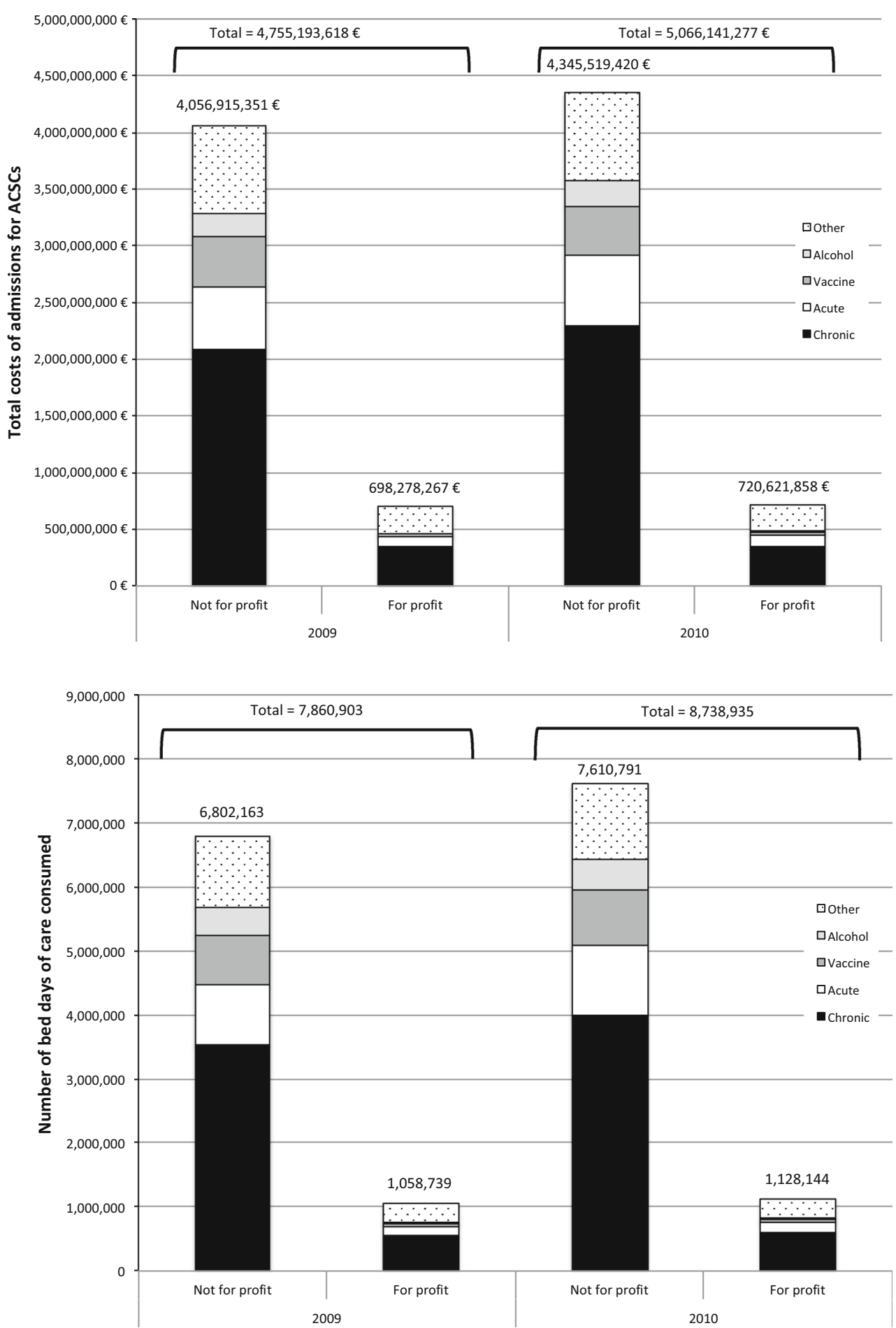

differences are in play, as well. Indeed, the likelihood ratio test for all categories of ACSCs that we examined except vaccine-related ACSC suggests larger regional influences in practice patterns. Similarly, our use of non-reallocated resource supply measures indicates that, while the strictly locally defined supply of general practitioners per capita is inversely associated with the rate of admission for chronic and total ACSCs, these relationships vanish when one accounts for the fact that some patients living in a particular department leave that department for admission for these ACSCs. Our findings suggest that reallocation of the physician supply might generate different results in other studies that found a relationship between higher rates of admission for ACSCs and a lower per-capita supply of 


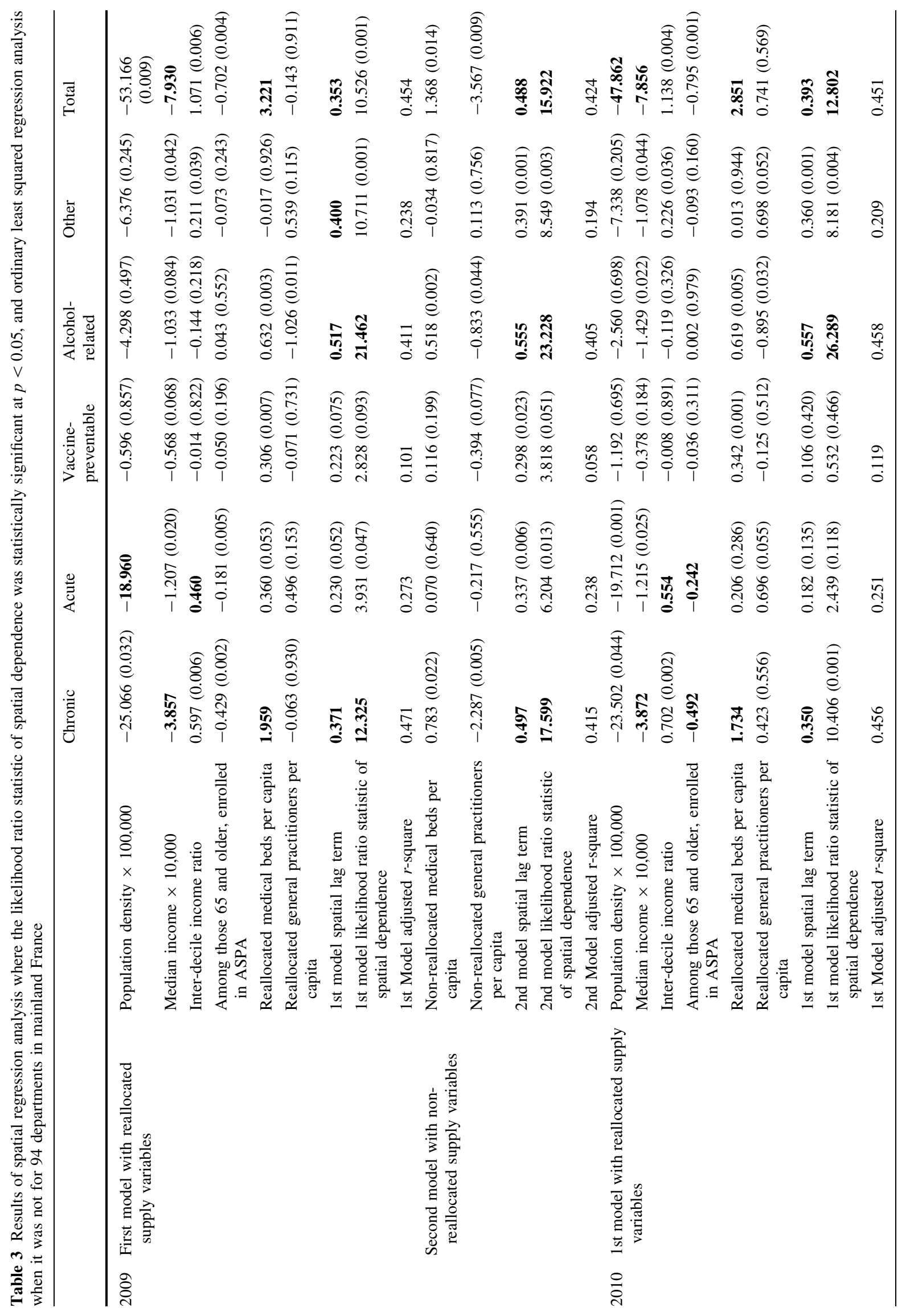


primary care physicians, but did not use Dartmouth Atlas supply reallocation methods $[9,10,21,24,25,33]$. In the US, researchers have demonstrated regional variation in physicians' propensity to diagnose [43, 44], test [45, 46], and intervene [45, 47] that has been, in part, attributed to regional differences in the way physicians practice medicine. Further, as has been shown in the US, lack of consensus about best treatment options [2,4] might contribute to the regional variation that we saw. In France, future work exploring geographic variation in per-capita admission rates might specifically examine physicians' discretionary decision-making and test whether practice protocol implementation might reduce regional practice variation.

In 2010, the 1.635 million admissions for ACSCs cost French taxpayers about 5 billion euros a year, more than one-half of the French healthcare system deficit that year [48]; these admissions consumed about 8.74 million bed days of care - equivalent to one 255-bed hospital operating at full capacity in each of the 94 departments that we examined. As has been found elsewhere [9-11, 14, 18, 19], we found that lower income levels were related to higher rates of admission for ACSCs. Interestingly, we found that higher numbers of medical beds per capita were associated with higher admission rates for ACSCs, suggesting a form of supplier-induced demand phenomenon [2]. Comparisons of rates of ACSCs in France to those in other countries suggests that France experiences higher rates than most other countries we examined; however, comparability in definitions of ACSCs and availability of data from the same time period tended to preclude exact comparisons.

Our findings suggest that substantial healthcare resources might be unleashed should France successfully reduce admissions for ACSCs. The magnitude of the potential cost and resource savings-representing $2.9 \%$ of the 175 billion euros that France spent on all healthcare and $6.3 \%$ of the 81.2 billion euros that France spent on hospital care in 2010 [49] — suggests that policymakers should make efforts to reduce admissions for ACSCs in France and monitor progress in these efforts. But our results suggest that targeted efforts-attentive screening of admissions for alcohol-related ACSCs in the northwest, for chronic ACSCs in the northeast, and for acute ACSCs in the southeast-may be wise. That we did not find a relationship between greater availability of general practitioners and lower rates of admission for ACSCs suggests that arbitrarily increasing the supply of general practitioners may not help reduce ACSC admission rates; rather, low incomes and a high availability of medical beds seem to be driving higher admission rates for most ACSCs. While our retrospective analysis cannot imply causation, our findings suggest that further study in this area is warranted.

Our study has several limitations. First, we did not have access to clinical data that could determine whether the 
admissions that we examined were warranted. Our inability to differentiate admissions that were and were not appropriate suggest that not all costs incurred associated with admissions for ACSCs could be saved; future work in this area might try to divine which ACSC admissions were truly preventable. Without intervention, it seems logical that, as populations grey and accumulate chronic diseases in developed countries, admissions for chronic and vaccine-preventable ACSCs (which are concentrated at the extremes of life) are likely to increase. Second, we could not examine outcomes; it is unclear whether admission for ACSCs results in better health outcomes. However, it seems to be the consensus that such admissions constitute a 'failure' of outpatient care that, in general, unnecessarily consumes expensive resources. Our findings suggest that such resource consumption is, indeed, quite expensive. Third, had we used a different geographic scale, we might have uncovered more variation or different relationships. For instance, an analysis of variation in diabetes treatment the Provence-Alpes-Côte d'Azur region that was performed at the 'canton' level showed higher extreme ratios [50] than we found for ACSCs at the department level. Further, the study of ACSC in three metropolitan areas in France [25] found a different relationship between primary care physician and ACSC rates than we found; this might be due, in part, to the different level of geographic analysis in the two studies. Finally, we were not able to correct for health status, or to use additional sources of data (like medication utilization) to identify other comorbid conditions: factors that might have explained the admission rates that we found [23].

Despite these limitations, policymakers should consider methods to reduce variation in - and overall admissions for-ACSCs. Seemingly, such efforts would have a high payoff. France's centralized planning and resource allocation process might help with the execution of strategies designed to reduce rates of ACSCs, such as development of consensus around best treatment patterns, identification of early ambulatory care interventions, and implementation of care pathways. In addition, international collaboration may identify new methods for reducing ACSCs in France and might facilitate equivalent cross-country comparisons, learning, and improvement.

Conflict of interest The authors have no conflicts of interest to report.

\section{Appendix: an example of bed reassignment}

In 2009 and 2010, hospitals in the Ain department (department 01) used 581 medical beds to provide 14,399 hospitalizations for ACSCs. Although 12,968 admissions were for patients who lived in Ain, the balance of patients lived in 66 different French departments; for example, 437 admissions were for patients from the neighboring Jura department (department 39). Those 437 bed days represented $3.1 \%$ of all 14,092 admissions for ACSCs that were provided by hospitals in Jura, a department with 549 medical beds. Therefore, we reallocated 17.02 medical beds from Ain to Jura for the purposes of determining bed supply for Jura patients. However, 12,140 admissions for patients who lived in Ain occurred in hospitals outside of Ain, 6683 of which were obtained in Rhône (department 69). Using its 3759 medical beds, Rhône hospitals provided 90,073 hospitalizations for ACSCs in 2009-2010. Therefore, we reallocated $7.4 \%$ of these beds, or 278.9 surgical beds from Rhône to Ain. After allocation from and to other French departments, we calculated that Ain had an adjusted supply of 1033 medical beds, while Jura had an adjusted supply of 614 medical beds, and Rhône had an adjusted supply of 3053 surgical beds.

\section{References}

1. McCulloch, P., Nagendran, M., Campbell, W.B., Price, A., Jani, A., Birkmeyer, J.D., Gray, M.: Strategies to reduce variation in the use of surgery. Lancet 382(9898), 1130-1139 (2013)

2. Wennberg, J.E.: Tracking medicine: a researcher's quest to understand health care. Oxford University Press, New York (2010)

3. Wennberg, J.E.: The Dartmouth atlas project. http://www.dart mouthatlas.org (2012). Accessed July 112014

4. Birkmeyer, J.D., Sharp, S.M., Finlayson, S.R., Fisher, E.S., Wennberg, J.E.: Variation profiles of common surgical procedures. Surgery 124, 917-923 (1998)

5. Corallo, A.N., Croxford, R., Goodman, D.C., Bryan, E.L., Srivastava, D., Stukel, T.A.: A systematic review of medical practice variation in OECD countries. Health Policy 114(1), 5-14 (2014)

6. Weeks, W.B., Paraponaris, A., Ventelou, B.: Geographic variation in rates of common surgical procedures in France in 2008-2010, and comparison to the US and Britain. Health Policy 118(2), 215-221 (2014)

7. Freund, T., Campbell, S.M., Geissler, S., Kunz, C.U., Mabler, C., Peters-Klimm, F., Szecsenyi, J.: Strategies for reducing potentially avoidable hospitalizations for ambulatory care sensitive conditions. Ann Fam Med 11(4), 363-370 (2013)

8. Ambulatory care-sensitive conditions. http://www.dartmoutha tlas.org/data/table.aspx?ind=198. Accessed July 11 2014. In: The Dartmouth atlas of health care, The Dartmouth Institute for Health Policy and Clinical Practice: Lebanon, NH

9. Chen, L.W., Zhang, W., Sun, J., Mueller, K.J.: The magnitude, variation, and determinants of rural hospital resource utilization associated with hospitalization due to ambulatory care sensitive conditions. J. Public Health Manag. Prac. 15(3), 216-222 (2009)

10. Chang, C.H., Stukel, T.A., Flood, A.B., Goodman, D.C.: Primary care physician workforce and Medicare beneficiaries' health outcomes. JAMA 305(20), 2096-2105 (2011)

11. Sanchez, M., Vellanky, S., Herring, J., Liang, J., Jia, H.: Variations in Canadian rates of hospitalization for ambulatory care sensitive conditions. Healthc. Q. 11(4), 20-22 (2008) 
12. Ansari, Z., Carson, N., Serraglio, A., Barbetti, T., Cicuttini, F.: The Victorian ambulatory care sensitive conditions study: reducing demand on hospital services in Victoria. Aust. Health Rev. 25(2), 71-77 (2002)

13. Ansari, Z., Rowe, S., Ansari, H., Sindall, C.: Small area analysis of ambulatory care sensitive conditions in Victoria, Australia. Popul. Health Manag. 16(3), 190-200 (2013)

14. Agabiti, N., Pirani, M., Schifano, P., Cesaroni, G., Davoli, M., Bisanti, L., Caranci, N., Costa, G., Forastiere, F., Marinacci, C., Russo, A., Spadea, T., Perucci, C.A.: Income level and chronic ambulatory care sensitive conditions in adults: a multicity population-based study in Italy. BMC Public Health 9, 457 (2009)

15. Magan, P., Otero, A., Alberquilla, A., Ribera, J.: Geographic variations in avoidable hospitalization in the elderly, in a health system with universal coverage. BMC Health Serv Res 8, 42 (2008)

16. Sheridan, A., Howell, F., Bedford, D.: Hospitalisations and costs related to ambulatory care sensitive conditions in Ireland. Ir. J. Med. Sci. 181, 527-533 (2012)

17. Niti, M., Ng, T.P.: Avoidable hospitalisation rates in Singapore, 1991-1998: assessing trends and inequities of quality in primary care. J. Epidemiol. Community Health 57, 17-22 (2003)

18. Blunt, I.: Focus on preventable admissions-trends in emergency admissions for ambulatory care sensitive conditions, 2001 to 2013. The Health Foundation and the Nuffield Trust: http://www.health. org.uk/publications/focus-on-preventable-admissions (2013). Accessed 11 July 2014

19. Tian, I., Dixon, A., Gao, H.: Data briefing-emergency hospital admissions for ambulatory care-sensitive conditions: identifying the potential for reductions. The Kings Fund: http://www.king sfund.org.uk/publications/data-briefing-emergency-hospitaladmissions-ambulatory-care-sensitive-conditions (2012). Accessed 11 July 2014

20. Naylor, C., Imison, C., Addicott, R., Buck, D., Goodwin, N., Harrison, T., Ross, S., Sonola, L., Tian, Y., Curry, N.: The Kings' Fund: transforming our health care system. http://www.king sfund.org.uk/sites/files/kf/field/field_publication_file/10Priorities Final2.pdf (2013). Accessed 11 July 2014, The King's Fund

21. Macinko, J., Dourado, I., Aquino, R., Bonolo, P.F., Lima-Costa, M.F., Medina, M.G., Mota, E., de Oliveira, V.B., Turci, M.A.: Major expansion of primary care in Brazil linked to decline in unnecessary hospitalization. Health Aff. 29(12), 2149-2160 (2010)

22. Junqeira, R.M.P., Duarte, E.C.: Hospitalizations due to ambulatory care-sensitive conditions in the Federal District, Brazil, 2008, R.S. Pública, Editor 2011, Universidade de Brasília. Brasília, DF, Brasil

23. Eggli, Y., Besquins, B., Seker, E., Halfon, P.: Comparing potentially avoidable hospitalization rates related to ambulatory care sensitive conditions in Switzerland: the need to refine the definition of health conditions and to adjust for population health status. BMC Health Serv. Res. 14, 25 (2014)

24. Burgdorf, F., Sundmacher, L.: Potentially avoidable hospital admissions in Germany: an analysis of factors influencing rates of ambulatory care sensitive hospitalizations. Deutsches Ärzteblatt Int. 111(13), 215-223 (2014)

25. Gusmano, M.K., Weisz, D., Rodwin, V.G., Lang, J., Qian, M., Bocquier, A., Moysan, V., Verger, P.: Disparities in access to health care in three French regions. Health Policy 114(1), 31-40 (2014)

26. Thygesen, L.C., Christiansen, T., Garcia-Armesto, S., AnguloPueyo, E., Martinez-Lizaga, N., Bernal-Delgado, E.: Potentially avoidable hospitalizations in five European countries in 2009 and time trends from 2002 to 2009 based on administrative data. Eur. J. Public Health 25(Suppl 1), 35-43 (2015)
27. Agence Technique de l'Information sur l'Hospitalisation (ATIH). http://www.atih.sante.fr/echelle-nationale-de-couts-par-ghm (2014). Accessed 22 October 2014

28. WHO mental health atlas: World Health Organization: Geneva (2011)

29. World Health Organization. Projections of mortality and burden of disease, 2004-2030 for 2008 by World Bank income groups, standard DALYs, (3\% discounting, age weights). http://www. who.int/healthinfo/global_burden_disease/projections2004/en/ . [cited 2014 September 19]

30. Gustavsson, A., Svensson, M., Jacobi, F., Allgulander, C., Alonso, J., Beghi, E., Dodel, R., Ekman, M., Faravelli, C., Fratiglioni, L., Gannon, B., Jones, D.H., Jennum, P., Jordanova, A., Jonsson, L., Karampampa, K., Knapp, M., Kobelt, G., Kurth, T., Lieb, R., Linde, M., Ljungcrantz, C., Maercker, A., Melin, B., Moscarelli, M., Musayev, A., Norwood, F., Preisig, M., Pugliatti, M., Rehm, J., Salvador-Carulla, L., Schlehofer, B., Simon, R., Steinhausen, H.C., Stovner, L.J., Vallat, J.M., Van den Bergh, P., van Os, J., Vos, P., Xu, W., Wittchen, H.U., Jonsson, B., Olesen, J., C.D. Group: Cost of disorders of the brain in Europe 2010. Eur. Neuropsychopharmacol. 21(10), 718-779 (2011). .[Erratum appears in Eur Neuropsychopharmacol. 2012 Mar;22(3):237-8 Note: den Bergh, Peter Van [corrected to Van den Bergh, Peter]]

31. The Dartmouth atlas of health care: indirect adjustment. http:// www.dartmouthatlas.org/downloads/methods/indirect_adjustment. pdf. Accessed 11 July 2014

32. Résultats du recensement de la population-2009: POP1Bpopulation par sexe et âge. http://www.recensement.insee.fr/ basesTableauxDetaillesTheme.action?idTheme $=12$ (2009). Accessed 11 July 2014. INSEE-Institut national de la statistique et des études économiques: Paris, France

33. The Dartmouth atlas of health care: research methods. http:// www.dartmouthatlas.org/downloads/methods/research_methods. pdf. Accessed 11 July 2014: Hanover, NH

34. Statistique annuelle des établissements de santé exercice-2010. http://www.data.gouv.fr/content/search?SortBy=Pertinence\& SortOrder $=0 \&$ SearchText=sae + statistique $(2012)$. Accessed 11 July 2014, Ministère du Travail, de l'Emploi et de la Santé

35. Eco-Santé 2013: Offre de biens et services medicaux; Démographie professions de santé et Distances accès; Médecins; Psychiatres et Neuro-psychiatres Ensemble; effectif http://www. ecosante.fr/. Accessed 22 October 2014

36. Appleby, J., Raleigh, V., Frosini, F., Bevan, G., Gao, H., Lyscom, T.: Variations in health care: the good, the bad and the inexplicable, The Kings' Fund: London (2011)

37. Birkmeyer, J.D., Reames, B.N., McCulloch, P., Carr, A.J., Campbell, W.B., Wennberg, J.E.: Understanding of regional variation in the use of surgery. Lancet 382(9898), 1121-1129 (2013)

38. McPherson, K., Wennberg, J.E., Hoving, O.B., Clifford, P.: Small-area variations in the use of common surgical procedures: an international comparison of New England, England, and Norway. N. Engl. J. Med. 307, 1310-1314 (1982)

39. Annuaire ANDASS des données sociales et de santé 2008 des Conseils généraux, Édition n 15, 2010, Association Nationale des Directeurs d'Action Sociale et de Santé des Conseils généraux: Paris

40. Peters, D.J.: American income inequality across economic and geographic space, 1970-2010. Soc. Sci. Res. 42(6), 1490-1594 (2013)

41. Berrigan, D., Tatalovich, Z., Pickle, L.W., Ewing, R., BallardBarbash, R.: Urban sprawl, obesity, and cancer mortality in the United States: cross-sectional analysis and methodological challenges. Int. J. Health Geogr. 13(1), 3 (2014)

42. Anselin, L., Syabri, I., Kho, Y.: GeoDa: an introduction to spatial data analysis. Geogr. Anal. 38(1), 5-22 (2006) 
43. Welch, H.G., Sharp, S.M., Gottlieb, D.J., Skinner, J.S., Wennberg, J.E.: Geographic variation in diagnosis frequency and risk of death among Medicare beneficiaries. JAMA 305(11), 1113-1118 (2011)

44. Song, Y., Skinner, J., Bynum, J., Sutherland, J., Wennberg, J.E., Fisher, E.S.: Regional variations in diagnostic practices.[Erratum appears in N Engl J Med. 2010 Jul 8;363(2):198]. N. Engl. J. Med. 363(1), 45-53 (2010)

45. Lucas, F.L., Sirovich, B.E., Gallagher, P.M., Siewers, A.E., Wennberg, D.E.: Variation in cardiologists' propensity to test and treat: is it associated with regional variation in utilization? Circul. Cardiovasc. Qual. Outcomes 3(3), 253-260 (2010)

46. Sirovich, B., Gallagher, P.M., Wennberg, D.E., Fisher, E.S.: Discretionary decision making by primary care physicians and the cost of U.S. health care. Health Aff. 27(3), 813-823 (2008)

47. Sirovich, B.E., Gottlieb, D.J., Welch, H.G., Fisher, E.S.: Variation in the tendency of primary care physicians to intervene. Arch. Intern. Med. 165(19), 2252-2256 (2005)
48. Thomson, S., Osborn, R., Squires, D., Jun, M.: International profiles of health care systems, 2013. http://www.common wealthfund.org/ /media/Files/Publications/FundReport/2013/ Nov/1717_Thomson_intl_profiles_hlt_care_sys_2013_v2.pdf, (2013), The Commonwealth Fund: New York, NY

49. Fenina, A., Le Carrec, M., Koubi, M.: Comptes nationaux de la santé, 2010. N 161—Septembre 2011. http://www.drees.sante. gouv.fr/IMG/pdf/seriestat161.pdf (2011), Direction de la recherche, des études, de l'évaluation et des statistiques (DREES)

50. Bocquier, A., Cortarendona, S., Nauleau, S., Jardin, M., Verger, P.: Prevalence of treated diabetes: geographical variations at the small-area level and their association with area-level characteristics. A multilevel analysis in southeastern France. Diabetes Metab. 37(1), 39-46 (2011) 